\title{
Vegetable Freshness Perception in Dementia with Lewy Bodies and Alzheimer's Disease
}

\author{
Yuka Oishi ${ }^{a-c}$ Toru Imamura ${ }^{a-c}$ Tatsuo Shimomura ${ }^{d}$ Kyoko Suzuki ${ }^{\mathrm{e}}$ \\ a Department of Speech, Language, and Hearing Sciences, Niigata University of Health \\ and Welfare, Niigata, Japan; ${ }^{\mathrm{b}}$ Graduate School of Health and Welfare, Niigata University \\ of Health and Welfare, Niigata, Japan; ' ${ }^{\mathrm{D}}$ Department of Neurology, Niigata Rehabilitation \\ Hospital, Niigata, Japan; ${ }^{d}$ Department of Rehabilitation Medicine, Akita Prefectural Center \\ for Rehabilitation and Psychiatric Medicine, Daisen, Japan; ${ }^{\text {eDepartment of Behavioral }}$ \\ Neurology and Cognitive Neuroscience, Tohoku University Graduate School of Medicine, \\ Sendai, Japan
}

\section{Keywords}

Vegetable freshness - Luminance judgment - Dementia with Lewy bodies · Alzheimer's disease $\cdot$ Visual texture recognition

\begin{abstract}
Introduction: Although various visual function deficits have been reported in patients with Alzheimer's disease (AD) and dementia with Lewy bodies (DLB), vegetable freshness perception has not been thoroughly examined. Objective: To investigate vegetable freshness perception in patients with $A D$ and DLB and to clarify the relationship between vegetable freshness perception and various visuoperceptual functions. Methods: We enrolled 37 patients with probable DLB, 58 patients with probable $A D$, and 32 age-matched healthy controls. We assessed vegetable freshness perception and visuoperceptual functions, including vegetable brightness perception, contrast sensitivity, color perception, and stereopsis. Patients with DLB showed disproportionate deficits in vegetable freshness perception and vegetable luminance perception compared to patients with $A D$ and controls. Analyses of the groups with higher and lower vegetable freshness perceptions revealed significant differences in contrast sensitivity and visual texture recognition. Results: In the vegetable freshness test, we found significant differences among the 3 groups $(F=30.029, p<0.0001)$; the extent of impairment in patients with DLB was greater than that in patients with $A D$. In patients with $D L B$, the vegeta-
\end{abstract}


ble freshness judgments were significantly correlated with texture judgment scores and contrast sensitivity. Conclusion: Our findings revealed significantly impaired vegetable freshness perception in patients with DLB. Vegetable freshness perception may be related to visual texture recognition in patients with DLB.

(C) 2020 The Author(s)

Published by S. Karger AG, Basel

\section{Introduction}

Visuoperceptual function deficits have previously been identified in dementia with Lewy bodies (DLB) and Alzheimer's disease (AD). Patients with DLB have deficits in relatively basic visual perception, including visual acuity, contrast sensitivity [1-3], color vision [4, 5], and stereopsis $[3,6,7]$. In AD, such impairments include visual acuity [8-10], contrast sensitivity [11-13], color perception [11,14,15], and stereopsis [11,16]. Patients with DLB also show visuoperceptual and visuospatial impairments compared to those with AD [4,17-20]. Visual cognitive impairment commonly manifests at the early stages of illness in DLB [21-23].

Uno et al. [24] tested patients with AD and mild cognitive impairment, and their ability to determine vegetable freshness, finding a reduced ability to determine vegetable freshness in individuals with $\mathrm{AD}$ compared to that of healthy controls (HC). They noted that the ability to determine vegetable freshness likely declined with dementia progression. However, no study has compared the disturbed vegetable freshness perception between AD and DLB; no reports exist on the relationships between various levels of visual processing deficits and vegetable freshness perception. Our primary goal was to investigate vegetable freshness perception in neurodegenerative dementia and correlates of vegetable freshness perception and basic and higher visual functions. Considering the greater visuoperceptual impairment in $\mathrm{DLB}$ versus $\mathrm{AD}$, we hypothesized that the vegetable freshness judgment of patients with DLB is poorer than that of patients with AD.

\section{Materials and Methods}

\section{Participants}

We recruited 37 and 58 patients with probable DLB and AD, respectively, who attended 2 dementia clinics at the Akita Prefectural Center of Rehabilitation and Psychiatric Medicine and the Niigata Rehabilitation Hospital between February 2016 and May 2018 (Table 1). We recruited 32 control subjects from the local community through an advertisement. The 3 groups were comparable in terms of age and sex. We assessed and matched cognitive impairment severity using the Mini-Mental State Examination (MMSE) between the DLB and AD groups. We included patients with: (1) a diagnosis of probable AD based on the criteria of the National Institute of Neurological and Communicative Disorders and Stroke/Alzheimer's Disease and Related Disorders Association (NINCDS-ADRDA) [25] or a diagnosis of possible or probable DLB based on the clinical criteria of the Consortium on DLB International Workshop [26], (2) a score of $\geq 10$ on the MMSE, (3) a score of $0.5-2$ on the CDR, and (4) a visual acuity $\geq 0.5$ on the contrast sensitivity test $(100 \%)$. In the initial assessment, we performed a neurological examination, a neuropsychological assessment, a brain MRI or CT scan, electroencephalography, and blood analysis for several parameters, including vitamins $\mathrm{B}_{1}$ and $\mathrm{B}_{12}$ and thyroid function, on each patient. We used formal clinical criteria to exclude patients with vascular dementia and other dementias. We excluded patients with developmental abnormalities, serious psychiatric diseases, substance abuse, or significant neurologic antecedents, such as brain trauma, brain tumor, epilepsy, and inflammatory disease. 


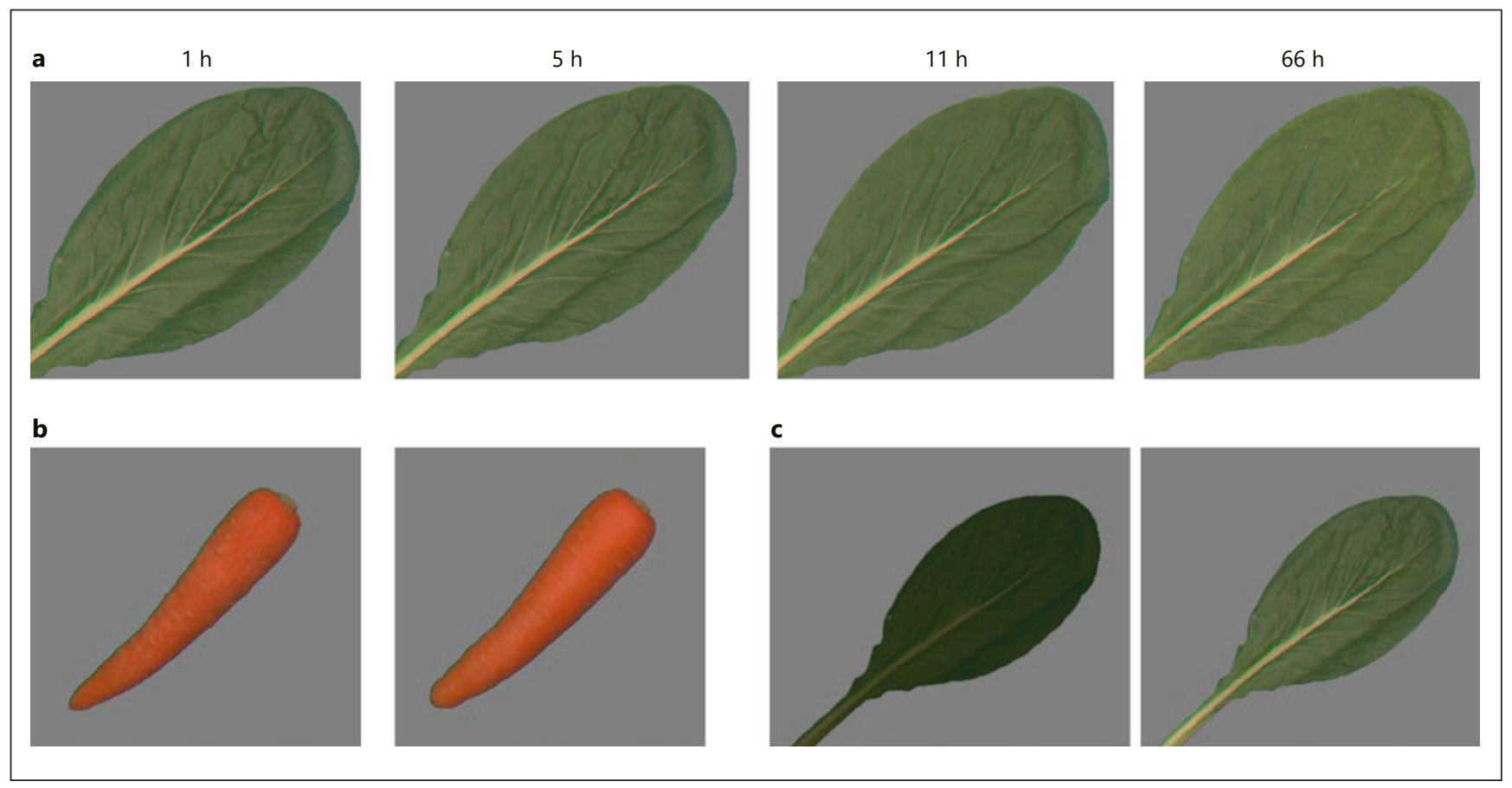

Fig. 1. Examples of the stimuli. a Examples of the patches selected as original stimuli. The number above stimulus is the time at which the photograph was taken. $\mathbf{b}$ Example showing the freshness of vegetables. c Example showing the luminance of vegetables.

We excluded HC with: (1) a history of neurological, psychiatric, or severe ocular diseases; (2) language deficits that hindered task execution; and (3) a visual acuity $>0.5$ on the contrast sensitivity test (100\%).

\section{Neuropsychological Examination}

We assessed the general cognitive functions of each patient using the MMSE [27], the Alzheimer Disease Assessment Scale (ADAS) [28], the Frontal Assessment Battery (FAB) [29], and the digit span (forward/backward) according to standard procedures.

The basic visual functions of each patient were assessed using the contrast sensitivity test (100, 2.5, and 1.25\%). The City University Color Vision Test (CUCVT; Part 2) and the color naming subtest of the visual perception test for agnosia [30] to assess color perception under illumination at 1,300 lux. We assessed stereopsis using the Random Dot Stereo Butterfly Test (Stereo Optical Co., Inc., Chicago, IL, USA). The Stereo test comprises 2 parts including butterfly shapes and circles with disparity ranges of 2,000-800 and 400-20 s of arc, respectively.

We assessed the higher visual functions using the shape detection screening and cube analysis subtests from the Visual Object and Space Perception Battery [31] and the positionin-space subtest from the Developmental Test of Visual Perception [32]. We used material identification tests as measures of visual texture recognition using 2 kinds of materials, i.e., real materials and visual images of real materials [14]. With the CDR we assessed global cognitive impairment severity [33].

\section{Freshness of Vegetables}

The freshness of vegetables can be determined by assessing vegetable freshness perception. We therefore used photographs of vegetables (carrot and Japanese mustard spinach [komatsuna]) previously degraded by heat in a thermostatic chamber from 0 to $66 \mathrm{~h}$

\section{Karger's}




\section{Disorders Extra}

Table 1. Demographic and clinical profiles of the participants

\begin{tabular}{|c|c|c|c|c|c|}
\hline Variables & $\operatorname{DLB}(n=37)$ & $\mathrm{AD}(n=58)$ & $\mathrm{HC}(n=32)$ & $F$ statistic & $p$ value \\
\hline Age, years & $81.2 \pm 6.7$ & $80.2 \pm 5.9$ & $79.4 \pm 4.1$ & 0.930 & 0.390 \\
\hline Female/male ratio ${ }^{\mathrm{a}}$ & $26 / 11$ & $42 / 16$ & $16 / 16$ & 5.024 & 0.081 \\
\hline Disease duration, years & $4.2 \pm 2.2$ & $5.1 \pm 3.2$ & & 2.389 & 0.127 \\
\hline Education, years & $9.7 \pm 2.6$ & $10.0 \pm 2.7$ & $11.4 \pm 1.9$ & 2.483 & 0.103 \\
\hline CDR & $1.2 \pm 0.6$ & $1.1 \pm 0.6$ & & 0.433 & 0.669 \\
\hline CDR score ratio $(0.5 / 1 / 2)$ & 8:18:11 & $14: 29: 15$ & & & \\
\hline \multicolumn{6}{|l|}{ Neuropsychology } \\
\hline MMSE (full score: 30) & $19.1 \pm 4.5^{c}$ & $20.2 \pm 4.7^{\mathrm{d}}$ & $28.6 \pm 0.9^{c, d}$ & 57.897 & $<0.0001$ \\
\hline Digit span forward & $4.8 \pm 0.8^{c}$ & $5.1 \pm 0.9^{d}$ & $5.9 \pm 0.9^{c, d}$ & 13.341 & $<0.0001$ \\
\hline Digit span backward & $2.6 \pm 1.1^{\mathrm{b}, \mathrm{c}}$ & $3.2 \pm 1.0^{\mathrm{b}}$ & $4.1 \pm 0.7^{\mathrm{c}}$ & 20.450 & $<0.0001$ \\
\hline FAB (full score: 18) & $13.6 \pm 8.9$ & $11.6 \pm 3.3$ & - & 2.336 & 0.130 \\
\hline ADAS (full score: 70) & $14.6 \pm 8.5$ & $16.6 \pm 7.7$ & - & 1.302 & 0.257 \\
\hline \multicolumn{6}{|l|}{ Visual function } \\
\hline Visual acuity & $0.88 \pm 0.28^{\mathrm{b}, \mathrm{c}}$ & $1.05 \pm 0.24^{\mathrm{b}}$ & $1.11 \pm 0.19^{\mathrm{c}}$ & 8.312 & $<0.0001$ \\
\hline Contrast sensitivity $2.5 \%$ & $0.26 \pm 0.20^{\mathrm{b}, \mathrm{c}}$ & $0.49 \pm 0.33^{\mathrm{b}}$ & $0.52 \pm 0.30^{c}$ & 9.215 & $<0.0001$ \\
\hline Contrast sensitivity $1.25 \%$ & $0.05 \pm 0.09^{b, c}$ & $0.17 \pm 0.14^{\mathrm{b}}$ & $0.24 \pm 0.21^{\mathrm{c}}$ & 13.796 & $<0.0001$ \\
\hline City University Color Vision Test Part 2 (full score: 6) & $4.6 \pm 1.5^{\mathrm{b}, \mathrm{c}}$ & $5.4 \pm 1.0^{\mathrm{a}}$ & $5.6 \pm 1.0^{c}$ & 7.760 & 0.001 \\
\hline Stereo test (visual angle) & $827.6 \pm 1,050.4)$ & $504.1 \pm 733.8$ & $391.9 \pm 773.5$ & 2.594 & 0.079 \\
\hline Color naming (full score: 8 ) & $7.0 \pm 1.0^{\mathrm{b}, \mathrm{c}}$ & $7.6 \pm 0.7^{\mathrm{b}}$ & $7.8 \pm 0.6^{\mathrm{c}}$ & 8.314 & $<0.0001$ \\
\hline Shape detection (full score: 20$)^{\mathrm{e}}$ & $18.3 \pm 1.7^{\mathrm{b}, \mathrm{c}}$ & $19.6 \pm 0.6^{\mathrm{b}}$ & $19.8 \pm 0.6^{c}$ & 22.844 & $<0.0001$ \\
\hline Cube analysis (full score: 10 ) $^{\mathrm{e}}$ & $4.9 \pm 2.7^{b, c}$ & $6.8 \pm 2.3^{\mathrm{b}, \mathrm{d}}$ & $9.1 \pm 0.9^{c, d}$ & 31.628 & $<0.0001$ \\
\hline Position in space (full score: 8$)^{\mathrm{f}}$ & $4.9 \pm 1.7^{\mathrm{b}, \mathrm{c}}$ & $6.4 \pm 1.4^{\mathrm{b}, \mathrm{d}}$ & $8.0 \pm 0^{c, d}$ & 43.304 & $<0.0001$ \\
\hline \multicolumn{6}{|l|}{ Visual texture cognitive function } \\
\hline Material judgment (real) (full score: 18) & $10.2 \pm 3.1^{b, c}$ & $12.2 \pm 3.0^{\mathrm{b}, \mathrm{d}}$ & $15.7 \pm 1.4^{\mathrm{c}, \mathrm{d}}$ & 35.138 & $<0.0001$ \\
\hline Material judgment (image) (full score: 18) & $7.7 \pm 2.5^{\mathrm{b}, \mathrm{c}}$ & $9.2 \pm 3.3^{\mathrm{b}, \mathrm{d}}$ & $13.9 \pm 2.1^{\mathrm{c}, \mathrm{d}}$ & 44.750 & $<0.0001$ \\
\hline
\end{tabular}

as stimuli [5] (Fig. 1a). We used this method because it is difficult to obtain vegetables at the same level of freshness; our method also prevented the subjects from using their other senses, such as smell, when assessing the freshness of the samples. We created 2 stimulation pairs at different levels of freshness for each vegetable (Fig. 1b). Immediately before administration of the test, we gave a detailed explanation and participants underwent 2 training trials. We presented image stimuli centrally for $10 \mathrm{~s}$ and asked the participants to select the fresher one (20 trials).

As a control task for the vegetable freshness determination test, we performed a luminance determination test. Using a photographic stimulation of komatsuna, we created 20 pairs of photographs with differing levels of luminance and asked the subjects to select the brighter photograph out of each pair (20 trials) (Fig. 1c). We used the same time limit and scoring method as those used for the freshness test.

\section{Statistical Analyses}

We compared neuropsychological tests among the 3 groups using one-way analysis of variance (ANOVA) with post hoc Scheffé tests. We classified all of the patients according to their CDR scores, which indicate the severity of dementia, into the a cognitive impairment group (CDR 0.5), a mild cognitive impairment group (CDR 1), and a moderate cognitive impairment group (CDR 2). Following ANCOVA, we performed a covariate analysis, with visual acuity, contrast sensitivity, and CUCVT score as covariates and vegetable freshness determination and vegetable 
Fig. 2. Results of the tests for the freshness and luminance of vegetables.

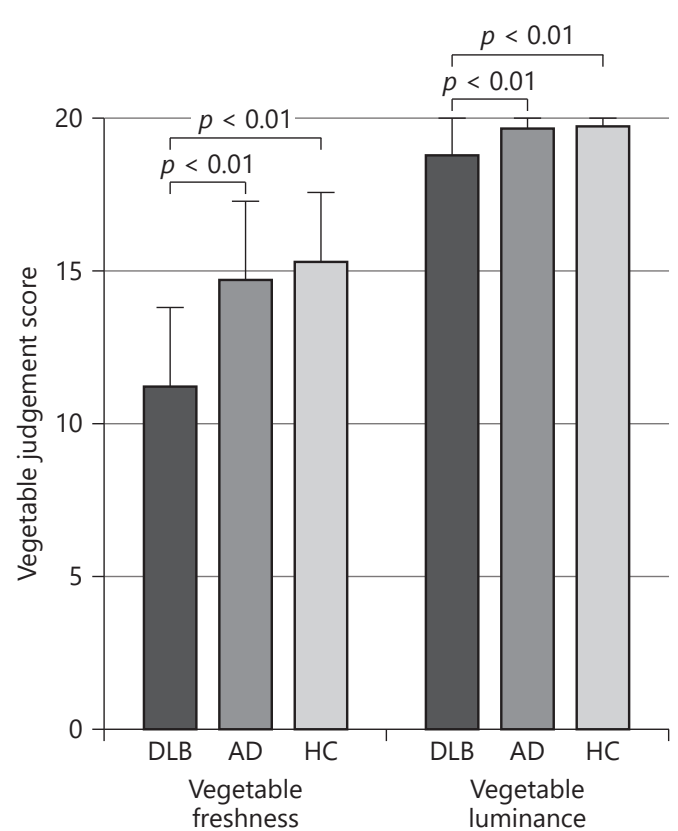

luminance determination as dependent variables. To evaluate the relationships between performances on the vegetable freshness test and other neuropsychological and visuoperceptual tests, we separately performed analyses in the higher vegetable freshness group $(\geq 12)$ and the lower vegetable freshness group $(\leq 11)$. As a cut-off point, we assumed the mean $-1.5 \mathrm{SD}$ of the normal subjects (i.e., 12/11). We further assessed the relationships between performance on the vegetable freshness test and other neuropsychological and visuoperceptual tests using the Pearson correlation coefficient or the Spearman rank correlation coefficient. Correlations of $r<0.3$ were interpreted as no/weak correlations and they were negligible. Only correlations of $r>0.3$ are reported. We applied partial $\eta^{2}\left({ }_{\mathrm{p}} \eta^{2}\right)$ to measure the effect size.

\section{Results}

\section{Neuropsychological Examinations}

In Table 1 we summarize the results. The groups did not differ significantly by age, sex, or education and the disease groups did not differ significantly in terms of disease duration or CDR. On measures of global cognitive functioning, i.e., the MMSE, the DLB and AD groups performed worse than the HC group. The 2 groups with dementia did not differ significantly from each other on these tests or on the ADAS or the FAB. On digit span backward, the DLB group had more impairments than the $\mathrm{AD}$ group (DLB vs. $\mathrm{AD}, p=0.005$ ). In Table 1 we summarize data on the basic and higher visual functional tests. One-way ANOVA revealed significant group differences - in which the performance of the DLB group was worse than that of the AD group - on all visual functional tests except that for stereopsis and visuoperceptual and visuospatial tests.

\section{Vegetable Freshness Perception}

In Figure 2, we summarize results on the vegetable freshness test. The median scores on the vegetable freshness test were 11.4 (2.8) for patients with DLB and 14.7 (2.5) for patients

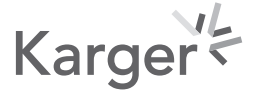


Table 2. Stratified score of visual texture tasks having classified seriousness levels on dementia

\begin{tabular}{|c|c|c|c|c|c|c|c|}
\hline \multirow[t]{2}{*}{ Tests } & \multicolumn{3}{|c|}{$\operatorname{DLB}(n=37)$} & \multicolumn{3}{|c|}{$\mathrm{AD}(n=58)$} & \multirow{2}{*}{$\begin{array}{l}\mathrm{HC} \\
(n=32)\end{array}$} \\
\hline & $\begin{array}{l}\text { CDR } 0.5 \\
(n=8)\end{array}$ & $\begin{array}{l}\text { CDR 1 } \\
(n=18)\end{array}$ & $\begin{array}{l}\text { CDR 2 } \\
(n=11)\end{array}$ & $\begin{array}{l}\text { CDR } 0.5 \\
(n=14)\end{array}$ & $\begin{array}{l}\text { CDR 1 } \\
(n=29)\end{array}$ & $\begin{array}{l}\text { CDR 2 } \\
(n=15)\end{array}$ & \\
\hline \multicolumn{8}{|l|}{ Vegetable freshness } \\
\hline judgment (full score: 20) & $12.6 \pm 2.7$ & $10.9 \pm 2.8^{* *}$ & $11.1 \pm 2.8^{* *}$ & $16.0 \pm 2.1$ & $14.5 \pm 2.5$ & $13.9 \pm 2.7$ & $15.3 \pm 2.2$ \\
\hline \multicolumn{8}{|l|}{ Vegetable luminance } \\
\hline judgment (full score: 20) & $19.4 \pm 0.9$ & $18.6 \pm 1.1^{* *}$ & $18.6 \pm 1.5^{*}$ & $19.6 \pm 0.6$ & $19.8 \pm 0.5$ & $19.5 \pm 0.6$ & $19.8 \pm 0.7$ \\
\hline
\end{tabular}

Values are presented means \pm SD. Tasks were tested using one-way ANOVA and post hoc Scheffé tests. ${ }^{*} p<0.05 .{ }^{* *} p<0.01$.

with $\mathrm{AD}$. In the vegetable freshness test, we found significant differences among the 3 groups $\left(F=30.029, p<0.0001,{ }_{p} \eta^{2}=0.326\right)$; the extent of impairment in patients with DLB was greater than that in patients with AD (post hoc Scheffé tests: DLB vs. AD, $p<0.0001$; DLB vs. $\mathrm{HC}, p<0.0001)$. Conversely, there were no significant differences between patients with AD and the controls (post hoc Scheffé tests: AD vs. HC, $p=0.561$ ). The median scores of the vegetable brightness test were 18.8 (1.2) for patients with DLB and $19.7(0.6)$ for patients with AD. In the vegetable brightness test, the 3 groups differed significantly $(F=16.137, p<0.0001$, $\mathrm{p} \eta^{2}=0.207$ ); patients with DLB were more impaired than patients with AD (post hoc Scheffé tests: DLB vs. AD, $p<0.0001$; DLB vs. HC, $p<0.0001$ ); however, patients with AD and controls did not differ significantly (post hoc Scheffé tests: AD vs. HC, $p=0.914$ ). Like the results of ANCOVA, on the vegetable freshness test, there was a significant difference across the 3 groups $\left(F=18.225 ; p<0.0001 ; \mathrm{p} \eta^{2}=0.187\right)$; post hoc analyses revealed that the DLB group performed significantly worse than the AD groups (post hoc Scheffé tests: DLB vs. AD, $p<$ 0.0001 ; DLB vs. HC, $p<0.0001$ ); however, there was no significant difference between the AD and HC groups $(p=0.394)$.

\section{Stratified Comparison by Severity of Dementia}

Results on the stratified comparison by severity of dementia are summarized in Table 2. In a stratified comparison based on the CDR score, vegetable freshness judgment was impaired in the DLB group with mild or greater severity compared to that in the HC group $(p<0.0001)$. The vegetable brightness test revealed significant group differences $(F=6.590, p<0.0001$, $\mathrm{p} \eta^{2}=0.248$ ). Post hoc analyses revealed that the mild DLB group performed significantly worse than the HC group ( $p=0.002)$; the moderate DLB group performed significantly worse than the HC group ( $p=0.025)$. Conversely, in the $\mathrm{AD}$ group, vegetable freshness and vegetable brightness were preserved in each severity class.

\section{Correlations between Cognitive Functions/Basic Visual Functions and Vegetable}

Freshness Judgment

In Table 3 we summarize data from the analyses in the higher vegetable freshness perception group and the lower vegetable freshness perception group. One-way ANOVA revealed significant group differences in contrast sensitivity at $2.50 \%$ and material judgment; the performance of the lower perception group was worse than that of the higher perception group in patients with DLB. Contrast sensitivity at $2.50 \%$ and material judgment differed significantly between the groups $\left(F=5.031, p=0.031\right.$, and $\eta^{2}=0.130$ and $F=5.480, p=0.025$, and $\eta^{2}=0.160$, respectively). In patients with $A D$, digit span backward was different between the groups $\left(F=4.112, p=0.047,{ }_{p} \eta^{2}=0.071\right)$. 
Dementia and

Geriatric Cognitive

Disorders Extra
Dement Geriatr Cogn Disord Extra 2020;10:74-85

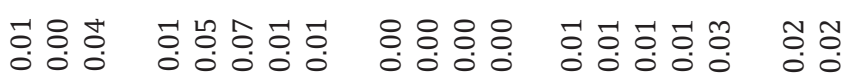

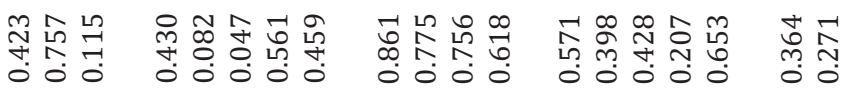

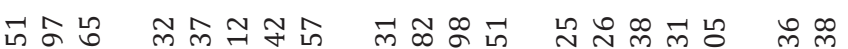

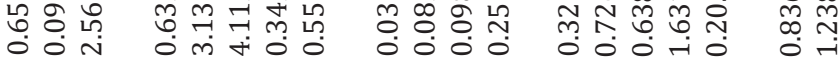

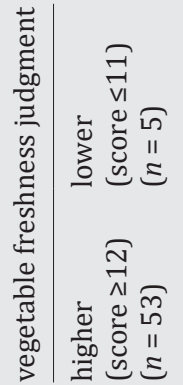
$-\wedge \infty$ 는

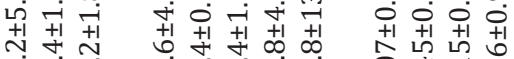
Non $\infty$

ln

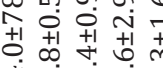
$+\frac{1}{+}$ क्ष

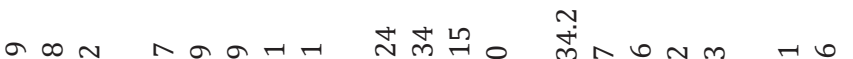

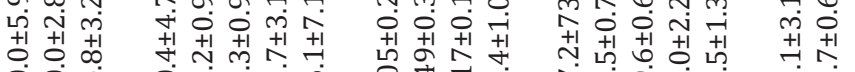

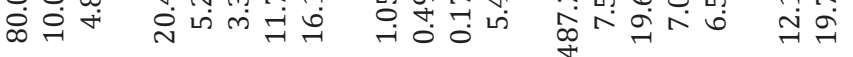

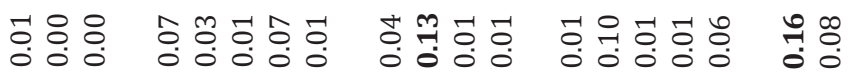

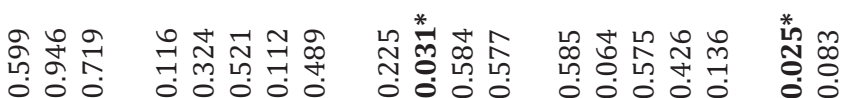

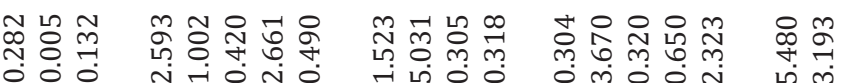

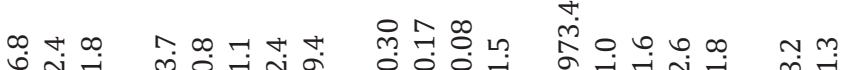

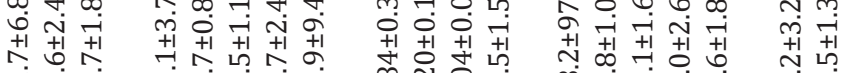
में

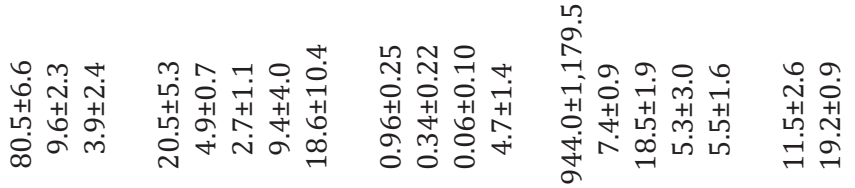

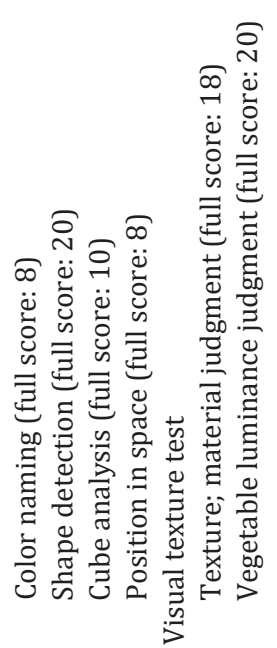


Table 4. Correlations between scores of the object decision test and neuropsychological variables

\begin{tabular}{|c|c|c|c|c|}
\hline \multirow[t]{3}{*}{ Variables } & \multicolumn{4}{|c|}{ Total scores on the vegetable freshness test } \\
\hline & \multicolumn{2}{|c|}{$\operatorname{DLB}(n=37)$} & \multicolumn{2}{|c|}{$\mathrm{AD}(n=58)$} \\
\hline & $r$ or rs & $p$ values & $r$ or rs & $p$ values \\
\hline \multicolumn{5}{|l|}{ Neuropsychology } \\
\hline MMSE & 0.311 & 0.0031 & 0.174 & 0.095 \\
\hline Digit span & 0.185 & 0.0137 & 0.269 & 0.021 \\
\hline \multicolumn{5}{|l|}{ Visual function } \\
\hline Visual acuity & 0.292 & 0.0077 & 0.155 & 0.123 \\
\hline Contrast sensitivity $2.5 \%$ & 0.328 & $0.0048^{*}$ & 0.234 & 0.077 \\
\hline Contrast sensitivity $1.25 \%$ & 0.046 & 0.0393 & 0.247 & 0.062 \\
\hline City University Color Vision Test & -0.090 & 0.0298 & -0.087 & 0.258 \\
\hline Stereo test (visual angle) & -0.072 & 0.0335 & -0.126 & 0.172 \\
\hline Shape detection ${ }^{\mathrm{a}}$ & -0.007 & 0.0483 & 0.042 & 0.377 \\
\hline Cube analysis ${ }^{\mathrm{a}}$ & 0.181 & 0.0142 & 0.074 & 0.291 \\
\hline Position in space ${ }^{\mathrm{b}}$ & 0.256 & 0.0063 & 0.110 & 0.207 \\
\hline \multicolumn{5}{|l|}{ Visual texture cognitive function } \\
\hline Texture: material judgment & 0.309 & $0.0031 *$ & 0.105 & 0.217 \\
\hline Vegetable luminance judgment & 0.123 & 0.0234 & -0.063 & 0.319 \\
\hline
\end{tabular}

Values in bold and with an asterisks indicate measures that remained significant after false discovery rate correction. Spearman correlation coefficients (rs) were used for contrast sensitivity, CUCVT, the Stereo test,

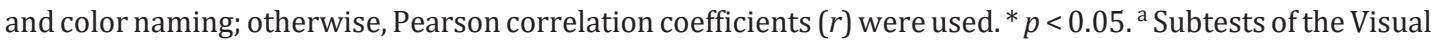
Object and Space Perception Battery. ${ }^{\mathrm{b}}$ Subtests of the Developmental Test of Visual Perception.

In Table 4 we summarize the correlations between cognitive functions/basic visual functions and vegetable freshness judgment. In patients with DLB, the vegetable freshness judgment was significantly correlated with texture judgment scores and contrast sensitivity at $2.5 \%(r=0.328$ and $p=0.048$ and $r=0.309$ and $p=0.031$, respectively).

\section{Discussion/Conclusion}

We investigated the visual ability in DLB and patients with AD to distinguish vegetable freshness. The results showed that the ability to determine vegetable freshness in patients with DLB was lower than that of healthy individuals - even after adjusting for the decline in basic visuoperceptual function. Among patients with DLB and a decreased ability to determine vegetable freshness, we observed the decrease to begin in those with mild dementia.

Our results also suggested an association between vegetable freshness perception and visual texture perception in patients with DLB.

In a previous study [14] on visual texture perception, we reported visual texture perception in patients with DLB and AD as lower than that of $\mathrm{HC}$ but as even poorer in patients with DLB. In our study, we used a binary choice task in the vegetable freshness perception task; subjects were presented with 2 photographs of vegetables at different stages of systemic decay induced by placing them in a constant temperature chamber for $66 \mathrm{~h}$. Most materials, including vegetables, have distinct 3-dimensional structures on their surfaces. Given that material-specific shaded textures are produced [34], visual texture perception may be associated with vegetable freshness perception. Although luminance was an important element of vegetable freshness perception among healthy individuals [35-37], the results of our study suggest that the visual perception of vegetable freshness in patients with degenerative 
dementia is influenced not only by a low-level visuoperceptual dysfunction but also by the disorder of visual texture perception.

Vegetable freshness perception, as shown by previous studies in healthy individuals, is not influenced by color information, with the luminance statistics of vegetable surfaces instead being important in determining freshness [35-37]. Visual information is first transmitted to the striate area (V1) located in the most posterior region of the cerebral cortex. Once processed in V1, information is received via 2 distinct pathways in the visual field located anterior to V1 [38], where information processed by individual neurons in V1 includes that associated with localized direction, spatial frequency, color, and luminance within an image in a very limited visual field [34]. V1 is therefore believed to be responsible for processing information on luminance.

DLB is characterized by a low glucose metabolism and blood flow in the occipital lobe including the striate area mentioned above and the visual association cortex [19, 39-43]. Recent neurofunctional imaging studies have also shown a low blood flow in the occipital lobe and the lateral side of the parietal lobe [44-46]. Various low-level visuoperceptual disorders have been reported in patients with DLB or AD; many studies have investigated the effects of these 2 disorders on visual cognition [4-6, 13,47-50]. Therefore, it is possible that luminance perception and contrast sensitivity are disturbed from the early stages of DLB and that visuoperceptual dysfunction could influence the perception of freshness of vegetables.

In the DLB group, with the exception of stereoscopic vision, all basic functions of visual perception - such as contrast sensitivity and color perception - decreased. These results are consistent with those of previous studies. There was also a correlation between vegetable freshness perception and contrast sensitivity, which demonstrated that decreased contrast sensitivity influenced vegetable freshness perception.

In a study by Uno et al. [24] on vegetable freshness perception in patients with $\mathrm{AD}$ and mild cognitive impairment, correlations between performance in vegetable freshness perception and both the MMSE and the FAB suggested that vegetable freshness perception declined with dementia progression in AD. We classified patients with DLB based on disease severity; vegetable freshness perception did not decline in patients with very mild DLB. However, it was lower than that of the HC group in patients with DLB who were classified as mild and moderate, which suggested that vegetable freshness perception declined with dementia progression. There was, however, no association between the progression of dementia and performance in vegetable freshness perception in patients with AD. A future longitudinal investigation with a larger sample will determine whether vegetable freshness perception declines with dementia progression in patients with $\mathrm{AD}$ as well.

The decline in visual vegetable freshness perception starts in the early stages of DLB, suggesting that impaired basic visual perception and texture perception play roles in the decline. In patients with DLB, the observed decreases in blood flow in the occipital lobe and the lateral side of the parietal lobe suggest that the decline in these functions is associated with a functional decline in the occipital lobe in DLB. Given that olfactory disturbance - which can influence the perception of vegetable freshness - has been reported in patients with Perkinson disease [51] and DLB [52], prospective studies are warranted to assess the relationship between vegetable freshness perception and olfactory disturbance. This study excluded patients in nursing homes, and this might have introduced a selection bias. Longitudinal investigations are required to confirm these patients' feeding behavior.

\section{Acknowledgement}

We thank all of the participants for their participation in this study. We also appreciate Dr. Kaoru Abe and Dr. Toshifumi Watanabe for helping with the recruitment of participants. 


\section{Statement of Ethics}

This study and all of the procedures were approved by the Ethics Committee of the Niigata University of Health and Welfare (No.17640-160120). This study was performed according to the rules of good clinical practice and complies with the rules for human experimentation stated in the World Medical Association Declaration of Helsinki. Written informed consent was obtained from all of the participants.

\section{Conflict of Interest Statement}

The authors have no conflict of interests to declare.

\section{Funding Sources}

This work was supported by a Grant in Aid for Scientific Research (grant No. 17K01480) from MEXT to Y.O. and a Grant-in-Aid for Scientific Research on Innovative Areas from MEXT (grant No. 15H05915 and 19H04890) to K.S.

\section{Author Contributions}

Conception of this research project: Y.O. and K.S. Organization of this research project: Y.O., T.I., and K.S. Execution of this research project: Y.O., T.I., T.S., and K.S. Design of the analysis: Y.O., T.I., and K.S. Execution of the analysis: Y.O. and T.I. Drafting of this paper: Y.O.

\section{References}

1 Regan D, Maxner C. Orientation-selective visual loss in patients with Parkinson's disease. Brain. 1987 Apr; 110(Pt 2):415-32.

2 Tebartz van Elst L, Greenlee MW, Foley JM, Lücking CH. Contrast detection, discrimination and adaptation in patients with Parkinson's disease and multiple system atrophy. Brain. 1997 Dec;120(Pt 12):2219-28.

3 Armstrong RA. Oculo-visual dysfunction in Parkinson's disease. J Parkinsons Dis. 2015;5(4):715-26.

4 Wood JS, Firbank MJ, Mosimann UP, Watson R, Barber R, Blamire AM, et al. Testing visual perception in dementia with Lewy bodies and Alzheimer disease. Am J Geriatr Psychiatry. 2013 Jun;21(6):501-8.

5 Oishi Y, Imamura T, Shimomura T, Suzuki K. Visual texture agnosia in dementia with Lewy bodies and Alzheimer's disease. Cortex. 2018 Jun;103:277-90.

6 Haug BA, Kolle RU, Trenkwalder C, Oertel WH, Paulus W. Predominant affection of the blue cone pathway in Parkinson's disease. Brain. 1995 Jun;118(Pt 3):771-8.

7 Bertrand JA, Bedetti C, Postuma RB, Monchi O, Génier Marchand D, Jubault T, et al. Color discrimination deficits in Parkinson's disease are related to cognitive impairment and white-matter alterations. Mov Disord. 2012 Dec;27(14):1781-8.

8 Uhlmann RF, Larson EB, Koepsell TD, Rees TS, Duckert LG. Visual impairment and cognitive dysfunction in Alzheimer's disease. J Gen Intern Med. 1991 Mar-Apr;6(2):126-32.

9 Friedman DS, Munoz B, Massof RW, Bandeen-Roche K, West SK. Grating visual acuity using the preferentiallooking method in elderly nursing home residents. Invest Ophthalmol Vis Sci. 2002 Aug;43(8):2572-8.

10 Ciocler Froiman P, Dantas PE. Assessment of visual acuity in patients with dementia using teller acuity cards. Strabismus. 2013 Jun;21(2):93-7.

11 Cronin-Golomb A, Corkin S, Rizzo JF, Cohen J, Growdon JH, Banks KS. Visual dysfunction in Alzheimer's disease: relation to normal aging. Ann Neurol. 1991 Jan;29(1):41-52.

12 Bassi CJ, Solomon K, Young D. Vision in aging and dementia. Optom Vis Sci. 1993 Oct;70(10):809-13.

13 Crow RW, Levin LB, LaBree L, Rubin R, Feldon SE. Sweep visual evoked potential evaluation of contrast sensitivity in Alzheimer's dementia. Invest Ophthalmol Vis Sci. 2003 Feb;44(2):875-8.

14 McCleary R, Shankle WR, Mulnard RA, Dick MB. Ishihara test performance and dementia. J Neurol Sci. 1996 Oct;142(1-2):93-8. 
15 Pache M, Smeets CH, Gasio PF, Savaskan E, Flammer J, Wirz-Justice A, et al. Colour vision deficiencies in Alzheimer's disease. Age Ageing. 2003 Jul;32(4):422-6.

16 Thiyagesh SN, Farrow TF, Parks RW, Accosta-Mesa H, Young C, Wilkinson ID, et al. The neural basis of visuospatial perception in Alzheimer's disease and healthy elderly comparison subjects: an fMRI study. Psychiatry Res. 2009 May;172(2):109-16.

17 Mori E, Shimomura T, Fujimori M, Hirono N, Imamura T, Hashimoto M, et al. Visuoperceptual impairment in dementia with Lewy bodies. Arch Neurol. 2000 Apr;57(4):489-93.

18 Calderon J, Perry RJ, Erzinclioglu SW, Berrios GE, Dening TR, Hodges JR. Perception, attention, and working memory are disproportionately impaired in dementia with Lewy bodies compared with Alzheimer's disease. J Neurol Neurosurg Psychiatry. 2001 Feb;70(2):157-64.

19 Mosimann UP, Mather G, Wesnes KA, O’Brien JT, Burn DJ, McKeith IG. Visual perception in Parkinson disease dementia and dementia with Lewy bodies. Neurology. 2004 Dec;63(11):2091-6.

20 Lambon Ralph MA, Powell J, Howard D, Whitworth AB, Garrard P, Hodges JR. Semantic memory is impaired in both dementia with Lewy bodies and dementia of Alzheimer's type: a comparative neuropsychological study and literature review. J Neurol Neurosurg Psychiatry. 2001 Feb;70(2):149-56.

21 Cagnin A, Bussè C, Jelcic N, Gnoato F, Mitolo M, Caffarra P. High specificity of MMSE pentagon scoring for diagnosis of prodromal dementia with Lewy bodies. Parkinsonism Relat Disord. 2015 Mar;21(3):303-5.

22 Guidi M, Paciaroni L, Paolini S, De Padova S, Scarpino O. Differences and similarities in the neuropsychological profile of dementia with Lewy bodies and Alzheimer's disease in the early stage. J Neurol Sci. 2006 Oct;248(12):120-3.

23 Tiraboschi P, Salmon DP, Hansen LA, Hofstetter RC, Thal LJ, Corey-Bloom J. What best differentiates Lewy body from Alzheimer's disease in early-stage dementia? Brain. 2006 Mar;129(Pt 3):729-35.

24 Uno Y, Ito S, Saito N, Tanji SK. Visual texture agnosia in Alzheimer's disease -a investigation using the vegetable freshness judgment test. Jpn J Neuropshychol. 2014;30:297.

25 McKhann GM, Knopman DS, Chertkow H, Hyman BT, Jack CR Jr, Kawas CH, et al. The diagnosis of dementia due to Alzheimer's disease: recommendations from the National Institute on Aging-Alzheimer's Association workgroups on diagnostic guidelines for Alzheimer's disease. Alzheimers Dement. 2011 May;7(3):263-9.

26 McKeith IG, Dickson DW, Lowe J, Emre M, O’Brien JT, Feldman H, et al.; Consortium on DLB. Diagnosis and management of dementia with Lewy bodies: third report of the DLB Consortium. Neurology. 2005 Dec;65(12): 1863-72.

27 Folstein MF, Folstein SE, McHugh PR. "Mini-mental state". A practical method for grading the cognitive state of patients for the clinician. J Psychiatr Res. 1975 Nov;12(3):189-98.

28 Mohs RC, Rosen WG, Davis KL. The Alzheimer's disease assessment scale: an instrument for assessing treatment efficacy. Psychopharmacol Bull. 1983;19(3):448-50.

29 Dubois B, Slachevsky A, Litvan I, Pillon B. The FAB: A frontal assessment battery at bedside. Neurology. 2000 Dec;55(11):1621-6.

30 Japan Society for Higher Brain Dysfunction. Visual perception test for agnosia. Tokyo: Shinko igaku shuppan; 1997.

31 Warrington EK, James M. Visual object and space perception battery. Bury St Edmunds, UK: Thames Valley Test, Company; 1991.

32 Maslow P, Frostig M, Lefever DW, Whittlesey JR. The Marianne Frosting Development Test of Visual Perception, 1963 standardization. Percept Mot Skills. 1964 Oct;19(2):463-99.

33 Morris JC. The Clinical Dementia Rating (CDR): current version and scoring rules. Neurology. 1993 Nov; 43(11):2412-4.

34 Komatsu H. Higher brain function of Shitsukan perception: perception of material and surface quality. Jpn J Sci Biol. 2012 Jul;63:284-94.

35 Arce-Lopera C, Masuda T, Kimura A, Wada Y, Okajima K. Luminance distribution modifies the perceived freshness of strawberries. Iperception. 2012 Jun;3(5):338-55.

36 Arce-Lopera C, Masuda T, Kimura A, Wada Y, Okajima K. Luminance distribution as a determinant for visual freshness perception: evidence from image analysis of a cabbage leaf. Food Qual Prefer. 2013 Mar;27(2): 202-7.

37 Arce-Lopera C, Masuda T, Kimura A, Wada Y, Okajima K. Model of vegetable freshness perception using luminance cues. Food Qual Prefer. 2015 Mar;40:279-86.

38 Milner AD, Goodale MA. Two visual systems re-viewed. Neuropsychologia. 2008 Feb;46(3):774-85.

39 Imamura T, Ishii K, Sasaki M, Kitagaki H, Yamaji S, Hirono N, et al. Regional cerebral glucose metabolism in dementia with Lewy bodies and Alzheimer's disease: a comparative study using positron emission tomography. Neurosci Lett. 1997 Oct;235(1-2):49-52.

40 Ishii K, Yamaji S, Kitagaki H, Imamura T, Hirono N, Mori E. Regional cerebral blood flow difference between dementia with Lewy bodies and AD. Neurology. 1999 Jul;53(2):413-6.

41 Imamura T, Ishii K, Hirono N, Hashimoto M, Tanimukai S, Kazui H, et al. Occipital glucose metabolism in dementia with lewy bodies with and without Parkinsonism: a study using positron emission tomography. Dement Geriatr Cogn Disord. 2001 May-Jun;12(3):194-7.

42 Colloby SJ, Fenwick JD, Williams ED, Paling SM, Lobotesis K, Ballard C, et al. A comparison of (99m)Tc-HMPAO SPET changes in dementia with Lewy bodies and Alzheimer's disease using statistical parametric mapping. Eur J Nucl Med Mol Imaging. 2002 May;29(5):615-22. 


\section{Geriatric Cognitive Disorders Extra}

43 Gilman S, Koeppe RA, Little R, An H, Junck L, Giordani B, et al. Differentiation of Alzheimer's disease from dementia with Lewy bodies utilizing positron emission tomography with [18F]fluorodeoxyglucose and neuropsychological testing. Exp Neurol. 2005 Feb;191 Suppl 1:S95-103.

44 Lim SM, Katsifis A, Villemagne VL, Best R, Jones G, Saling M, et al. The 18F-FDG PET cingulate island sign and comparison to 123I- $\beta$-CIT SPECT for diagnosis of dementia with Lewy bodies. J Nucl Med. 2009 Oct;50(10): 1638-45.

45 Imabayashi E, Yokoyama K, Tsukamoto T, Sone D, Sumida K, Kimura Y, et al. The cingulate island sign within early Alzheimer's disease-specific hypoperfusion volumes of interest is useful for differentiating Alzheimer's disease from dementia with Lewy bodies. EJNMMI Res. 2016 Dec;6(1):67.

46 Imabayashi E, Soma T, Sone D, Tsukamoto T, Kimura Y, Sato N, et al. Validation of the cingulate island sign with optimized ratios for discriminating dementia with Lewy bodies from Alzheimer's disease using brain perfusion SPECT. Ann Nucl Med. 2017 Aug;31(7):536-43.

47 Nissen MJ, Corkin S, Buonanno FS, Growdon JH, Wray SH, Bauer J. Spatial vision in Alzheimer's disease. General findings and a case report. Arch Neurol. 1985 Jul;42(7):667-71.

48 Lakshminarayanan V, Lagrave J, Kean ML, Dick M, Shankle R. Vision in dementia: contrast effects. Neurol Res. 1996 Feb;18(1):9-15.

49 Neargarder SA, Stone ER, Cronin-Golomb A, Oross S 3rd. The impact of acuity on performance of four clinical measures of contrast sensitivity in Alzheimer's disease. J Gerontol B Psychol Sci Soc Sci. 2003 Jan;58(1):54-62.

50 Cronin-Golomb A, Gilmore GC, Neargarder S, Morrison SR, Laudate TM. Enhanced stimulus strength improves visual cognition in aging and Alzheimer's disease. Cortex. 2007 Oct;43(7):952-66.

51 Singh S, Schwankhaus J. Olfactory disturbance in Parkinson disease. Arch Neurol. 2009 Jun;66(6):805.

52 Kanai M, Sekiguchi N. Taste disorder in neurodegenerative disease. J Geriatr Psychiatry. 2017:28. 